\title{
AN INTRODUCTION TO JUDAISM AND CHINESE PHILOSOPHY
}

At the end of 20th century, while summarizing the encounters between Jews and the Chinese, Benjamin Schwarz noticed two issues. The first was that although the encounters took place several times since the arrival of the Kaifeng Jewish community at the Northern Song Dynasty, no "meaningful cultural encounter"1 ever took place until the "past few years" - which were in the mid-to-late 1990s. His second observation was that whatever impact did take place in those encounters occurred on Jewish side. While the perceptions of the "Kaifeng Jews of late imperial China," "were so deeply affected by the universalistic claims of Chinese culture," of Jews was never close to their true culture. Even in modern times, "more often than not, stereotypes about the nature of Judaism as a religion would be derived from Christian missionary sources even by Chinese who were decidedly not Christian."3

Today, 18 years into the 21st century, the encounter between these cultures has developed a dramatically fast speed and into a much broader scope, way beyond what Schwartz witnessed in late 1990s, which was basically limited to some academic interest in each other's culture. Schwartz probably never would have predicted that in 2016, China almost replaced the US in becoming the largest foreign investor in Israel. Though that trend ended with Chinese government's regulatory changes in mid-2017, Chinese entrepreneurs continue to visit and to study in Israel with an enthusiasm resembling that of pilgrims. In 2017, the heads of the two countries signed an agreement to upgrade the relationship between the two countries into "an innovative comprehensive partnership" based on a perception that Israeli or Jewish people are culturally strong in innovation and creativity.

Within academia, vast Jewish and Israeli works - from Rabbinic classics such as the Mishnah or the writings of Rambam, to modern Israeli literature such as the works of Amos $\mathrm{Oz}$-were translated into Chinese and were received very well by Chinese readers. Research institutes on Jewish or Israeli studies were established throughout

PING ZHANG, Professor, Department of East Asian Studies, Tel Aviv University. Specialties: inter-traditional dialogue between Chinese and Jewish traditions, comparative philosophy. E-mail: pzhang@post.tau.ac.il

Journal of Chinese Philosophy 45:1-2 (March-June 2018) 4-8

(C) 2019 Journal of Chinese Philosophy 
China, and academic activities around these subjects have been held regularly.

Perhaps there is no better example than Chung-ying Cheng's efforts and the publication of this special issue. As a leading Confucian thinker, Chung-ying Cheng came twice to Israel since 2011, to seek the possibility of a dialogue between the two traditions. During his 2016 visit, a historical dialogue was conducted between him and the Jewish philosopher, Joseph Agassi. The idea of the special issue came up during his visit, and he invited me to the University of Hawaii at Manoa to spend my sabbatical year, to continue the discussion about the dialogue and the special issue. And since then he participated in almost every conference on the dialogue. It's not the first time in history that a Confucian thinker engaged in dialogue with another tradition, but it's definitely the first time that a Confucian thinker engaged in a dialogue with Jewish tradition with such enthusiasm and efforts.

In addition to the academic efforts, the worship of so-called "Jewish wisdom" became a phenomenon in Chinese popular culture. Production of fake books of "Jewish wisdom," which proclaim themselves to teach people the secrets of Jewish business success but actually have no content related to real Jewish culture, has become quite a prosperous industry. ${ }^{4}$ In short, the popularity of Jewish culture in 21st century China reminds us of the 7th century, the golden periods of Buddhism in China, or the early 20th century, when Western culture was cherished as a great enhancement of Chinese tradition.

It seems that the two issues that Schwartz mentioned in his article had transformed tremendously in less than 20 years. This encounter is obviously culturally meaningful. The eagerness to learn each other's culture is so tremendous that even the economic relationship is based on the cultural perceptions. Though both cultures are intent on seeking mutual cultural understanding, obviously at present China is making greater efforts, exhibiting more enthusiasm, and making much more progress. Today, nobody would argue that the Chinese perception of Judaism is only a secondhand impression distorted by Christianity.

Nevertheless, just like any encounter between civilizations, problems - mainly caused by misperceptions-are no less significant than achievements. In China, fake "Jewish wisdom" publications are causing confusion among ordinary people as well as scholars and may lead the encounter into the wrong direction. In Israel, misperceptions of Chinese culture are costing business people precious time and money in their business interactions with their Chinese partners, causing great frustration. These are only two of many examples showing how this encounter can go wrong. Indeed, encounters between 
civilizations can lead to conflict and discrimination, including antiSemitism. While witnessing what might be one of the most magnificent encounters in human history, a key question is: how do we retain the fascination of the encounter while avoiding potential disasters?

This question provides one of the main justifications for academic efforts accompanying the encounter. As scholars dedicate their lives to studying the other's culture, they are supposed to understand more, address misperceptions, and likely also make some corrections and provide some guidelines. In the case of current encounters between Jews and China, academic research is, willingly or not, a part of the encounter; it cannot be separated from what is going on in economic life and popular culture. As an academic subject, this interaction is not only extremely interesting, but also poses a scholarly duty toward the human situation. Both Chinese and Jewish traditions cherish this duty, as "oneness of knowledge and action" is highly valued in both.

What can the academic community possibly do? In my opinion, at least three kinds of research may contribute to and influence the ongoing encounter: translation and related research, case studies of specific events within this encounter, and comparative or dialogic studies between the two traditions.

Given the relatively huge gap between Mandarin and Hebrew languages, one might reasonably assume that for the most part, the cultural encounter can take place only through translations. As mentioned above, progress has been made in translating each other's literature, yet much work remains ahead. For example, only a very limited number of traditional classics were translated between Hebrew and Chinese, and viceversa. Of the six Seders of the Mishnah, only two were translated into Chinese. And none of the Talmudic tractates is available in Chinese. On the other side, only the most prominent classics, such as Dao De Jing, the Analects, Mencius, and a few other key texts were translated into Hebrew in their entirety.

Research on the translated texts should be undertaken while the translation work is in process, so that the completed works can be properly reviewed and the quality of the works in future can be improved. It is also important that theoretical or philosophical research be conducted, so we can attain a clearer picture on the role that translation plays in the encounter between these civilizations.

Real-time case studies on encounter events, undertaken as the events unfold, may provide profound insight into the dialogue as it unravels and enable a process of pondering and reflection on the recent experience, while also shedding light on what may lie ahead. Such undertakings could involve a study on the influence of a specific 
text on the other side of the encounter, or research into a certain phenomenon observed, such as "Jewish wisdom" being faked in China.

Dialogical or comparative studies between the two cultures actually comprise essential elements of the encounter itself, as they provide us with fundamental understandings of each other. Such efforts could involve a study of two similar or related concepts from both traditions, or a study of two similar historical periods or historical figures. While similarity provides the basis for these studies, it is the obscured differences hidden behind the similarities should be pursued, because apparent similarities are a more common source of confusion than obvious differences, and sincere misperception often emerges from this kind of misunderstanding.

This special issue of "Judaism and Chinese Philosophy" is designed with these key questions in mind and on the basis of these three subjects, which are covered by the selected papers. It is a landmark event that prominent scholars such as Chung-ying Cheng, Joseph Agassi, and Irene Eber are participating in the activities related to this special issue or contributed their papers to us. I'd also like to express my special gratitude to Dr. Linyu Gu, who guided the entire project with her exceptional wisdom and professional talents.

As Martin Buber famously said, "All real living is meeting." We are witnessing a fascinating meeting between two of the oldest traditions in the world. It is our participation that keeps this historical meeting alive and productive, and assures that it will, in Benjamin Schwartz's words, "enrich and complicate our comparative global discourse." 6

Towards the end of the production of this current special issue, we sadly learned that Professor Irene Eber passed away. She had contributed a wonderful paper to this issue. Irene Eber was among the first and certainly the best scholars who explored the Sino-Jewish dialogue as a serious academic subject. Her contributions on the historical and intellectual relationships between the Chinese and Jewish people, especially her studies on the Chinese translations of the Hebrew Bible, are remarkable achievements of this dialogue. In April 2016, Irene Eber agreed to participate in my conference "Is Dao/Torah Translatable? - Inter-traditional Dialogue between Chinese and Jewish Traditions (sponsored by Confucius Institute)." In her email of acceptance she remarked that "I am delighted to know that such a conference will at last take place in Israel." Although she was struggling with her illness almost from the day of accepting the invitation, and could not personally attend the conference, she finished writing the paper, and agreed to revise it to publish it in this special issue. She was still responding to my mails on 
proofreading the paper until several days before she passed away. Her dedication to the dialogue will always be an inspiration for us to continue conducting it.

TEL AVIV UNIVERSITY

Tel Aviv, Israel

\section{ENDNOTES}

Acknowledgment of Copyrights and Credentials: First, I thank the Confucius Institute and the Department of East Asian Studies of Tel Aviv University, who sponsored my conference of "Is Dao/Torah Translatable? - Inter-traditional Dialogue between Chinese and Jewish Traditions". The conference took place on Dec. 14-15, 2016 in Tel Aviv University. All authors of this issue participated in this conference, and three of the papers (Joseph Agassi, Irene Eber, Ronald Kiener) are related to the papers they presented during the conference. Secondly, I would like to thank Chung-ying Cheng and Linyu $\mathrm{Gu}$ for their profound comments on the introduction. Finally, I would like to thank Mrs. Hephzibah Levine and Ms. Sharon Small for contributing to the article's English style.

1. Benjamin I. Schwartz, "Jews and China: Past and Present Encounters," in Jonathan Goldstein, ed., The Jews of China: v. 1: Historical and Comparative Perspectives (New York: M.E. Sharpe, Inc., 1999), 303.

2. Ibid., 302.

3. Ibid., 303.

4. Cf., Ping Zhang, "When Chokhmah Met Zhi: Perception and Misperception of Jewish Wisdom in China since the 1990s," in Manfred Hutter, ed., Between Mumbai and Manila Judaism in Asia since the Founding of the State of Israel (Bonn: V\&R Unipress, Bonn University Press, 2013), 249-258.

5. Martin Buber, I and Thou, trans., Ronald George Smith (New York: Charles Scribner's Sons, 1958), 11.

6. Schwartz, "Jews and China," 304. 